\title{
RESISTÊNCIA HIDRÁULICA DA CROSTA FORMADA EM SOLOS SUBMETIDOS A CHUVAS SIMULADAS ${ }^{(1)}$
}

\author{
Viviane dos Santos Brandão(2), Demetrius David da Silva ${ }^{(3)}$, Hugo \\ Alberto Ruiz $^{(4)}$, Fernando Falco Pruski ${ }^{(3)}$, Carlos Ernesto G.R. \\ Schaefer ${ }^{(4)}$, Mauro Aparecido Martinez ${ }^{(3)} \&$ Sady Júnior \\ Martins da Costa de Menezes ${ }^{(5)}$
}

\begin{abstract}
RESUMO
Para avaliar a redução da taxa de infiltração em solos sujeitos ao encrostamento decorrente da aplicação de chuvas simuladas, foi realizado um experimento em esquema fatorial 5 x 6, sendo cinco solos (Argissolo Vermelho, Argissolo VermelhoAmarelo, Latossolo Vermelho-Amarelo, Neossolo Flúvico e Neossolo Quartzarênico) e seis energias cinéticas de chuva $\left(0,525,1051,2102,3153\right.$ e $\left.4204 \mathrm{~J} \mathrm{~m}^{-2}\right)$, com três repetições. A partir dos dados de taxa de infiltração da água no solo e da espessura da crosta, determinadas por micromorfometria, calcularam-se a condutividade e a resistência hidráulica da crosta. Todos os solos apresentaram redução da taxa de infiltração, quando a energia cinética de chuva simulada aplicada aumentou. A resistência hidráulica da crosta aumentou com a energia cinética (especialmente para os solos Argissolos Vermelho-Amarelos e Vermelho) até atingir um valor máximo, a partir do qual ocorreu diminuição, atribuída ao desgaste erosivo da crosta provocado pelo aumento do escoamento superficial, associado aos maiores valores de energia cinética da chuva simulada. Por meio de análise de regressão múltipla, foram determinadas a relação da resistência hidráulica da crosta com a energia cinética da chuva e as características químicas e físicas de cada solo. A variável resistência hidráulica da crosta mostrou-se adequada a ser utilizada nos modelos infiltração da água no solo para descrever a influência do encrostamento neste processo.
\end{abstract}

Termos de indexação: encrostamento, chuva simulada e resistência hidráulica da crosta.

\footnotetext{
(1) Parte da Tese de Doutorado do primeiro autor. Projeto financiado pela FAPEMIG. Recebido para publicação em março de 2004 e aprovado em outubro de 2005.

(2) Engenheira-Agrônoma, D.S. Especialista em Recursos Hídricos, Agência Nacional de Águas. CEP 70610-200 Brasília (DF). E-mail: vbrandao@ana.gov.br

(3) Professor do Departamento de Engenharia Agrícola, Universidade Federal de Viçosa - UFV. CEP 36470-000 Viçosa (MG). Bolsista do CNPq. E-mails: david@ufv.br; ffpruski@ufv.br; mmauro@ufv.br

(4) Professor do Departamento de Solos, UFV.Bolsista do CNPq. E-mails: hruiz@ufv.br; carlos.schaefer@ufv.br

(5) Estudante de graduação em Engenharia Agrícola, Departamento de Engenharia Agrícola, UFV. Bolsista da FAPEMIG.
} 


\title{
SUMMARY: CRUST HYDRAULIC RESISTANCE IN SOILS UNDER SIMULATED RAIN
}

\begin{abstract}
To evaluate the decrease in infiltration rate in crusting soils an experiment was carried out using a rainfall simulator. Treatments were distributed in a factorial schedule $5 \times 6$, using five soils (Red Ultisol, Red-Yellow Ultisol, Red-Yellow Oxisol, Fluvic Entisol and Arenic Entisol) and six rainfall kinetic energies (0, 525, 1051, 2102, 3153, and $4204 \mathrm{~J} \mathrm{~m}^{-2}$ ) with three replications. According to the water infiltration rate and crust thickness, as determined by micromorphometry, the crust hydraulic conductivity and hydraulic resistance were calculated. The crust hydraulic resistance increased with the kinetic energy of the rain (especially for Red-Yellow Ultisol and Red Ultisol) up to a maximum value. The following decrease of crust hydraulic resistance was attributed to the crust erosion caused by increasing runoff. Multiple regression analysis determined the relationship of crust hydraulic resistance with the rainfall kinetic energy as well as the chemical and physical characteristics of each soil. The hydraulic resistance appeared to be an appropriate variable to be used in models of water infiltration in the soil to describe the crust influence on this process.
\end{abstract}

Index terms: crusting, rainfall simulator, crust hydraulic resistance.

\section{INTRODUÇÃO}

A infiltração é o processo pelo qual a água atravessa a superfície do solo. A formação de crosta decorrente do impacto das gotas da chuva é um dos fatores que pode reduzir acentuadamente a infiltração e, conseqüentemente, aumentar o escoamento superficial, contribuindo para a erosão do solo.

O encrostamento é resultante de processos complexos e dinâmicos nos quais as partículas do solo são rearranjadas e consolidadas em uma estrutura superficial coesa, cuja espessura pode variar de $0,1 \mathrm{~mm}$ até valores superiores a $50 \mathrm{~mm}$ (Valentin \& Bresson, 1992). Apesar de sua espessura relativamente pequena, suas propriedades físicas são restritivas à passagem da água para dentro do perfil do solo.

Muitos são os modelos desenvolvidos para estimar a infiltração da água no solo e, de acordo com a sua natureza, podem ser classificados em empíricos e teóricos. Dentre os modelos teóricos, destacam-se o de Green e Ampt e o de Green e Ampt modificado por Mein e Larson (GAML) (Mein \& Larson, 1973). Tais modelos, apesar de serem baseados em equações que descrevem o movimento da água em meios porosos, comumente superestimam a infiltração por não incorporarem na sua estrutura o efeito do encrostamento. Brakensiek \& Rawls (1983), entretanto, propuseram uma adaptação da equação de infiltração de GAML para solos agrícolas sujeitos ao encrostamento.

Brakensiek \& Rawls (1983) desenvolveram modelo para descrever o processo de infiltração em solos com encrostamento superficial baseado na equação de Green e Ampt. Estes autores mostram a subdivisão do perfil do solo em duas camadas (crosta e subcrosta) e determinam então um valor de condutividade hidráulica equivalente (Ke), que associa a condutividade das duas camadas por meio de média harmônica segundo a equação 1 .

$$
\mathrm{Ke}=\frac{\mathrm{L}}{\frac{\mathrm{L}-\mathrm{zc}}{\mathrm{Ksc}}+\frac{\mathrm{zc}}{\mathrm{Kc}}}
$$

em que $\mathrm{L}=$ profundidade da frente de umedecimento, $\mathrm{m} ; \mathrm{zc}=$ espessura da crosta, $\mathrm{m} ; \mathrm{Kc}=$ condutividade hidráulica da crosta saturada, $\mathrm{m} \mathrm{s}^{-1}$, e $\mathrm{Ksc}=$ condutividade hidráulica da subcrosta saturada, $\mathrm{m} \mathrm{s}^{-1}$.

A avaliação do desenvolvimento do encrostamento pode ser feita por meio de características físicas e hídricas do solo, tais como: infiltração e condutividade hidráulica (McIntyre, 1958a, b; Edwards \& Larson, 1969; Golabi et al., 1995); ou por meio de observações morfológicas da crosta, usando técnicas de microscopia (Duley, 1939; Evans \& Buol, 1968; Chen et al., 1980; Bresson \& Boiffin, 1990; Faria et al., 1998; Santos, 2000), que permitem avaliar a sua espessura, a macroporosidade, a distribuição, a forma e a continuidade dos poros. Poucos são os trabalhos, entretanto, que tentam relacionar características físicas e hídricas do solo com aspectos micromorfológicos (Norton, 1987; Valentin \& Bresson, 1992; Slattery \& Bryan, 1992). Esta relação pode ser muito interessante no emprego dos modelos de infiltração em solos sujeitos ao desenvolvimento de encrostamento, uma vez que a determinação das características físicas e hídricas da crosta é essencial para a incorporação do seu efeito à estrutura do modelo.

Neste sentido, os objetivos do presente trabalho foram:

- avaliar a taxa de infiltração da água em algumas classes de solo submetidas a diferentes energias cinéticas de chuva simulada; 
- avaliar, por meio de análise micromorfológica, as características físicas e hídricas da crosta formada decorrente de aplicação de chuva simulada, e

- estabelecer modelo matemático que relacione a resistência hidráulica da crosta com algumas características físicas e químicas do solo e com a energia cinética da chuva.

\section{MATERIAL E MÉTODOS}

Para determinar a variação da taxa de infiltração da água no solo e do desenvolvimento do encrostamento, foi realizado experimento no Laboratório de Hidráulica do Departamento de Engenharia Agrícola da UFV, utilizando simulador de chuvas estacionário de bicos múltiplos e oscilantes, construído na UFV, conforme modelo proposto pelo National Soil Erosion Research Laboratory (NSERL/USDA-ARS), vinculado ao Departamento de Agricultura dos Estados Unidos.

Os tratamentos foram distribuídos conforme um delineamento inteiramente casualizado, num esquema fatorial $5 \times 6$, sendo cinco classes de solo (Argissolo Vermelho - PV, Argissolo VermelhoAmarelo - PVA, Latossolo Vermelho-Amarelo - LVA, Neossolo Flúvico - RUq e Neossolo Quartzarênico RQo) e seis níveis de energia cinética de impacto direto da gota de chuva sobre a superfície do solo $(0$, 525, 1051, 2102, 3153 e $4204 \mathrm{~J} \mathrm{~m}^{-2}$ ), com três repetições.

Todos os solos foram secos ao ar e peneirados em malha com abertura de $2 \mathrm{~mm}$. A caracterização encontra-se no quadro 1.

A unidade experimental constituiu-se de uma coluna de PVC de $250 \mathrm{~mm}$ de diâmetro e $25 \mathrm{~cm}$ de altura. O fundo da coluna foi fechado com uma placa de PVC, onde foi feito um orifício para permitir a livre drenagem da água da coluna. Com este mesmo objetivo, preencheu-se o fundo da coluna com $2 \mathrm{~cm}$ de areia (seca ao ar e peneirada em malha de $2 \mathrm{~mm}$ ). Acima dessa camada, a coluna foi preenchida com solo, sem que houvesse compactação, até à altura de $20 \mathrm{~cm}$. O solo foi, então, umedecido por fluxo ascendente para evitar qualquer alteração da sua superfície.

As colunas apresentavam, na parte superior, uma fenda retangular que possibilitava a coleta do escoamento superficial.

Todas as unidades experimentais foram submetidas à mesma energia cinética total (4204 $\mathrm{J} \mathrm{m}^{-2}$ ). A superfície do solo contido em três colunas (repetições), correspondentes a cada um dos tratamentos, ficou exposta ao impacto direto das gotas de chuva até que fossem aplicadas as energias cinéticas de 0, 525, 1051, 2102, 3153, $4204 \mathrm{~J} \mathrm{~m}^{-2}$. Por exemplo, as colunas correspondentes ao tratamento Argissolo-Vermelho e energia cinética $525 \mathrm{~J} \mathrm{~m}^{-2}$ ficaram descobertas até que fossem aplicados $525 \mathrm{~J} \mathrm{~m}^{-2}$; a partir desse momento, a superfície do solo foi coberta com uma manta sintética de alta permeabilidade (Bidim), com a finalidade de proteger o solo e cessar o desenvolvimento do encrostamento. As colunas permaneceram cobertas até que fosse aplicado o total de $4204 \mathrm{~J} \mathrm{~m}^{-2}$. Dessa forma, as colunas em que foi aplicada a energia cinética de $0 \mathrm{~J} \mathrm{~m}^{-2}$ permaneceram cobertas durante todo o teste e aquelas em que foi aplicada a energia cinética de $4204 \mathrm{~J} \mathrm{~m}^{-2}$ ficaram permanentemente expostas ao impacto direto da chuva simulada.

Para fins de determinação indireta da taxa de infiltração, o escoamento superficial foi coletado em um reservatório, no qual foi instalado um equipamento medidor de nível (OTT Thalimedes Shaft Encoder) que permitia o acompanhamento da variação do nível da água em intervalos de um minuto.

Com a mesma finalidade, quatro funis foram presos às paredes externas das colunas de solo para coletar a chuva, que foi armazenada em outro reservatório, no qual foi instalado linígrafo, desenvolvido conforme método proposto por Barbieri (1993), para possibilitar o registro contínuo da lâmina de chuva aplicada ao longo do tempo. Conhecendo a taxa de aplicação da chuva e a taxa

Quadro 1. Resultados de análises físicas e de carbono orgânico dos solos estudados

\begin{tabular}{|c|c|c|c|c|c|c|c|}
\hline Solo & Areia grossa & Areia fina & Silte & Argila & A.D.A. & G.F. & C.O. \\
\hline & & & $\mathrm{kg} \mathrm{kg}^{-1}$ & & - & $\%$ & $10^{-2} \mathrm{~kg} \mathrm{~kg}^{-1}$ \\
\hline RQo & 0,675 & 0,201 & 0,026 & 0,098 & 0,072 & 26,53 & 0,447 \\
\hline RUq & 0,206 & 0,310 & 0,177 & 0,307 & 0,011 & 96,42 & 0,481 \\
\hline PVA & 0,232 & 0,163 & 0,132 & 0,473 & 0,364 & 23,04 & 1,746 \\
\hline PV & 0,202 & 0,164 & 0,144 & 0,490 & 0,308 & 37,14 & 1,334 \\
\hline LVA & 0,141 & 0,083 & 0,081 & 0,695 & 0,331 & 52,37 & 1,746 \\
\hline
\end{tabular}

Sendo: A.D.A. = argila dispersa em água; G.F. = grau de floculação; C.O. = carbono orgânico. PV = Argissolo Vermelho; PVA = Argissolo Vermelho-Amarelo; LVA = Latossolo Vermelho-Amarelo; RUq = Neossolo Flúvico; e RQo = Neossolo Quartzarênico. 
de escoamento superficial, foi possível obter, por diferença, a taxa de infiltração de água no solo. A figura 1 apresenta a estrutura utilizada para realização do experimento.

Para avaliar o desenvolvimento do encrostamento superficial, foram enterrados verticalmente nas colunas de solo três cilindros de metal de aproximadamente $58 \mathrm{~mm}$ de diâmetro e $50 \mathrm{~mm}$ de altura: um deles destinado à análise micromorfológica, realizada segundo princípios descritos por Murphy (1986) e modificados por Schaefer (1994); outro para a análise da macroporosidade (Embrapa, 1997) e o último reservado para substituição em eventuais perdas.

Ao final de cada teste, as amostras de solo contidas nos anéis metálicos destinadas à análise micromorfológica foram secas em estufa a $45^{\circ} \mathrm{C}$ e, posteriormente, impregnadas com resina. A cura foi feita em ambiente ventilado até que a amostra de solo formasse um bloco rígido o suficiente para permitir o corte. Uma fatia delgada, com aproximadamente $5 \mathrm{~mm}$ de espessura, foi cortada longitudinalmente, sendo o corte feito pelo centro do bloco.

Como um dos objetivos deste trabalho era a avaliação das características do encrostamento, foi selecionada somente a parte superior da fatia delgada dos blocos para confecção das lâminas de vidro, que foi realizada no Centro de Desenvolvimento de Tecnologia Nuclear da Universidade Federal de Minas Gerais (CDTN/UFMG).
As lâminas foram levadas para microscópio OLYMPUS AX70 que, por meio de câmera de vídeo ligada a um microcomputador, permitia a obtenção de imagens usando o programa computacional PHOTOSHOP 6.0. As imagens foram manipuladas, usando os programas computacionais Visual Stitcher Beta e Quantiporo versão 1.0 (Fernandes Filho \& Viana, 2001), para a determinação da espessura da crosta.

Neste trabalho, foi implementada uma modificação no modelo de Brakensiek \& Rawls (1983), no que se refere à determinação do parâmetro Ke (Equação 1). Sabendo que os valores de taxa de infiltração estável da água no solo (Tie) aproximam-se dos valores de condutividade hidráulica equivalente, estabeleceuse uma relação de igualdade entre estes parâmetros, conforme sugerido por Silva \& Kato (1998). É importante lembrar que a Tie é aquela taxa alcançada para longos períodos de infiltração.

Uma vez determinadas a espessura da crosta (zc) e a altura da coluna de solo (L) e considerando que a condutividade hidráulica da subcrosta é a taxa de infiltração estável da coluna que não sofreu exposição direta à chuva simulada $\left(0 \mathrm{~J} \mathrm{~m}^{-2}\right)$, é possível calcular, a partir da equação 1 , a condutividade hidráulica da crosta $(\mathrm{Kc})$, bem como a resistência hidráulica da crosta (Rc) pela relação (Equação 2)

$$
\mathrm{Rc}=\frac{\mathrm{Zc}}{\mathrm{Kc}}
$$

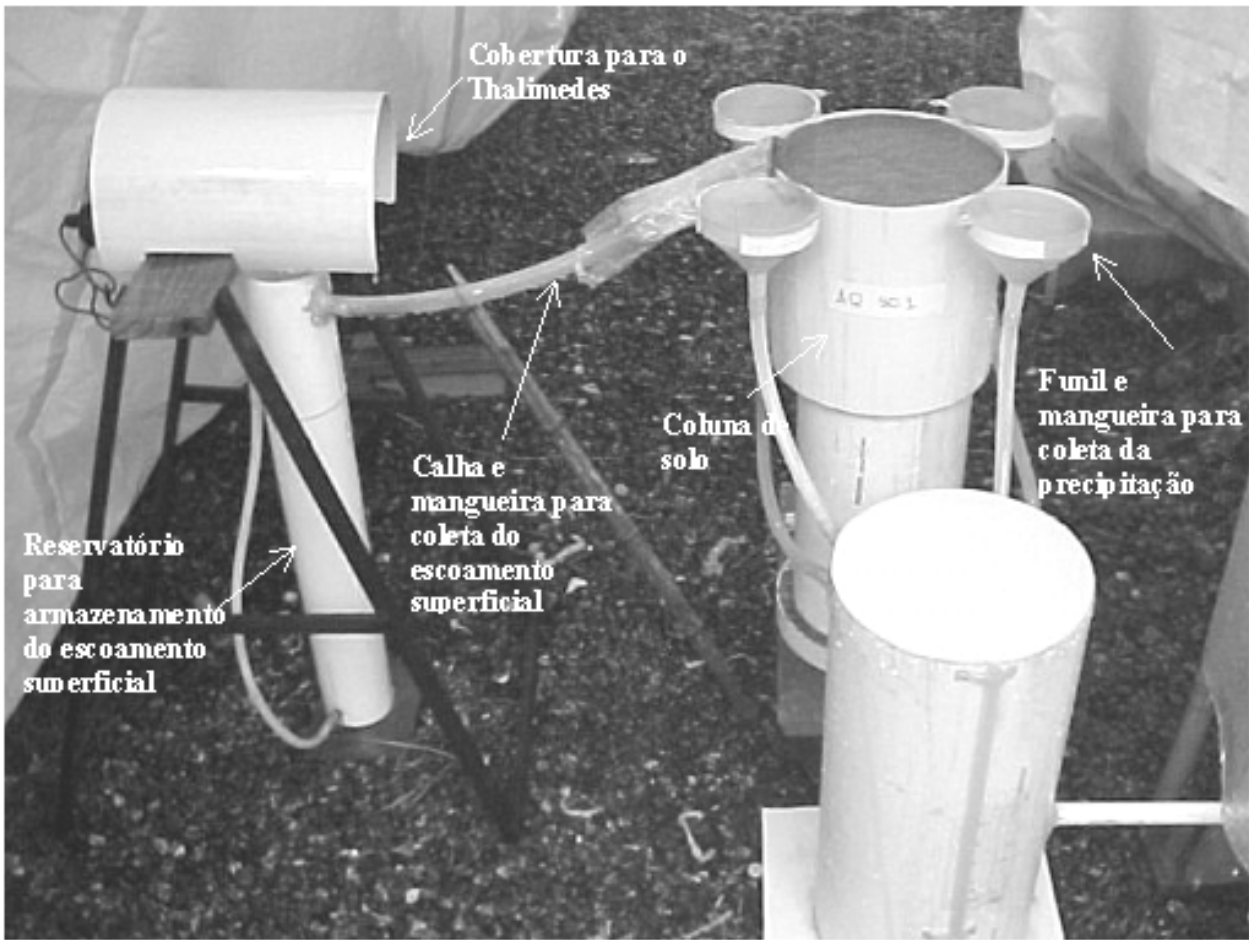

Figura 1. Estrutura construída para realização do experimento. 
Os valores médios de taxa da infiltração estável e da macroporosidade para cada classe de solo foram comparados por meio de teste de agrupamento de Scott-Knott a $5 \%$ de significância, uma vez verificada a homocedasticidade destas variáveis pelo teste de Cochran.

Foram feitas análises de regressão, utilizando o programa estatístico STATISTICA 6.0, com o objetivo de determinar equações ajustadas aos dados obtidos para cada solo, tendo, como variáveis dependentes, a taxa de infiltração e as características da crosta (espessura, condutividade e resistência hidráulica) e, como variável independente, a energia cinética da chuva.

Considerando as características químicas e físicas de cada solo, determinaram-se equações que estabelecem a relação entre a variável dependente resistência hidráulica da crosta e as variáveis independentes, a saber: teor de areia grossa, areia fina, areia total, silte, argila total e argila dispersa em água, grau de floculação, teor de carbono orgânico, macroporosidade e energia cinética da chuva.

\section{RESULTADOS E DISCUSSÃO}

Os valores médios de taxa de infiltração encontrados para as diferentes classes de solo são apresentados no quadro 2 . Na figura 2, são apresentados o gráfico e as equações ajustadas relacionando a taxa de infiltração com a energia cinética da chuva para cada classe de solo analisada.

Os maiores valores de taxa de infiltração foram observados para o Neossolo Quartzarênico e Latossolo Vermelho-Amarelo. O primeiro por conter $0,876 \mathrm{~kg} \mathrm{~kg}^{-1}$ de areia e o segundo, em conseqüência da sua estrutura granular muito pequena, por ser favorecido pelos altos teores de óxidos de $\mathrm{Fe}$ e $\mathrm{Al}$ e matéria orgânica típicas desta classe de solo (Oliveira et al., 1992).

O solo que apresentou menor taxa de infiltração foi o Argissolo Vermelho-Amarelo, provavelmente decorrente do seu baixo grau de estruturação, que, associado ao elevado conteúdo de argila dispersa em água (Quadro 1), favoreceu o preenchimento dos poros pela argila.

Quadro 2. Valores médios de taxa de infiltração estável (Tie) e macroporosidade, considerando a classe de solo

\begin{tabular}{lllccc}
\hline \multirow{2}{*}{ Variável } & \multicolumn{5}{c}{ Classe de solo } \\
\cline { 2 - 6 } & RQo & RUq & PVA & PV & LVA \\
\hline Tie $\left(10^{-5} \mathrm{~m} \mathrm{~s}^{-1}\right)$ & $4,3 \mathrm{~A}$ & $1,9 \mathrm{a}$ & $1,1 \mathrm{c}$ & $1,6 \mathrm{~b}$ & $3,1 \mathrm{~B}$ \\
Macroporosidade $\left(\mathrm{m}^{3} \mathrm{~m}^{-3}\right)$ & $0,329 \mathrm{~A}$ & $0,262 \mathrm{C}$ & $0,212 \mathrm{a}$ & $0,279 \mathrm{~B}$ & $0,221 \mathrm{a}$
\end{tabular}

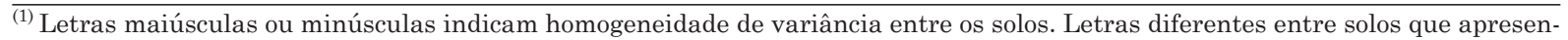
tam homogeneidade de variância indicam diferenças significativas pelo teste de agrupamento de Scott-Knott a 5\% de significância Sendo: PV = Argissolo Vermelho; PVA = Argissolo Vermelho-Amarelo; LVA = Latossolo Vermelho-Amarelo; RUq = Neossolo Flúvico; e RQo = Neossolo Quartzarênico.

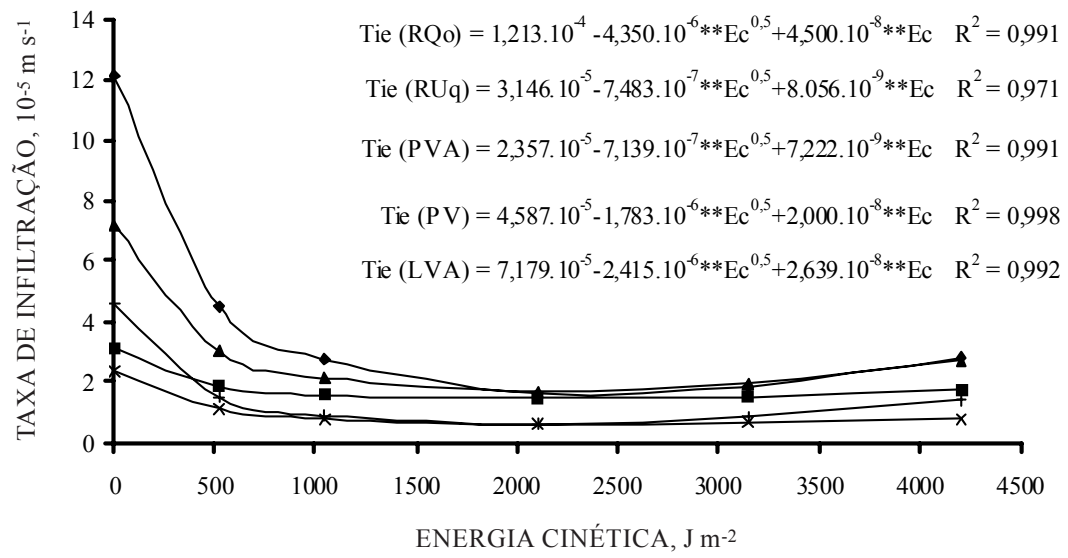

$\rightarrow \mathrm{RQo} \rightarrow-\mathrm{RUq} \rightarrow \mathrm{PVA} \rightarrow \mathrm{PV} \multimap \mathrm{LVA}$

Figura 2. Taxa de infiltração estável (Tie), considerando a energia cinética aplicada (Ec) e a classe de solo (** significativo a $1 \%$ pelo teste t). Sendo: PV = Argissolo Vermelho; PVA = Argissolo Vermelho-Amarelo; LVA = Latossolo Vermelho-Amarelo; RUq = Neossolo Flúvico, e RQo = Neossolo Quartzarênico. 
O Argissolo Vermelho, apesar de ter constituição físico-química semelhante à do Argissolo Vermelho-Amarelo, apresentou taxa de infiltração significativamente superior à daquele solo, provavelmente por apresentar maior teor de óxidos de Fe do que o PVA (Oliveira et al., 1992). Estes óxidos, ao se ligarem às lâminas de caulinita, promovem uma desorganização destas lâminas, o que favorece a infiltração da água. Possivelmente, no PVA, estas apresentam-se predominantemente orientadas facea-face, o que dificulta a passagem da água para dentro do perfil do solo.

Pode-se observar, na figura 2, que, para todas as classes de solo, houve uma redução da taxa de infiltração quando foram aplicados valores crescentes de energia cinética da chuva, o que é uma evidência do desenvolvimento de encrostamento.

Os solos que foram mais afetados pelo encrostamento, ou seja, aqueles que sofreram maior decréscimo de taxa de infiltração por unidade de energia cinética, foram o RQo e o $\operatorname{LVA}\left(4,510^{-6} \mathrm{e}\right.$ 2,6 $10^{-6} \mathrm{~m} \mathrm{~m}^{2} \mathrm{~J}^{-1} \mathrm{~s}^{-1}$, respectivamente), embora tenham mantido as maiores taxas de infiltração.

É possível observar, na figura 2, que os valores de taxa de infiltração atingem um valor mínimo para valores de energia cinética aplicada próximos de $2200 \mathrm{~J} \mathrm{~m}^{-2}$ e, posteriormente, ocorre um ligeiro aumento, mais evidente para o maior valor de energia cinética aplicada. Este ligeiro aumento pode ser explicado pelo possível desgaste da crosta provocado pelo arraste das partículas de solo pelo escoamento superficial.

No quadro 2, também são apresentados os valores de macroporosidade obtidos para cada classe de solo. Como a macroporosidade não variou significativamente com o aumento da energia cinética aplicada, não foi possível ajustar equações de regressão. A ausência de dependência entre estes parâmetros deveu-se ao fato de que a energia cinética do impacto da gota de chuva afetou a camada mais superficial do solo, enquanto a determinação da macroporosidade foi feita em anéis de $5 \mathrm{~cm}$ de altura, o que fez com que o efeito do encrostamento nestes parâmetros ficasse diluído, tornando este método inadequado para avaliação do encrostamento.

O valor de macroporosidade do Neossolo Quartzarênico foi significativamente maior que do Argissolo Vermelho e do Neossolo Flúvico, o que explica a maior taxa de infiltração observada naquele solo.

$\mathrm{Na}$ figura 3, são apresentados os gráficos e as equações ajustadas relacionando a espessura da crosta com a energia cinética aplicada, para as cinco classes de solo analisadas. Observa-se, nesta figura, que as maiores espessuras da crosta foram observadas para o Neossolo Quartzarênico e, as menores, para o Neossolo Flúvico.

Em todos os solos, com exceção do RQo, a energia cinética de impacto direto da gota foi utilizada para quebrar e deformar os agregados da superfície do solo e para reorganizar os agregados e partículas simples. Assim, as crostas formadas em solos predominantemente constituídos por partículas simples, tal como o RQo, tornaram-se mais espessas porque toda energia cinética foi empregada principalmente para reorganização das partículas simples.

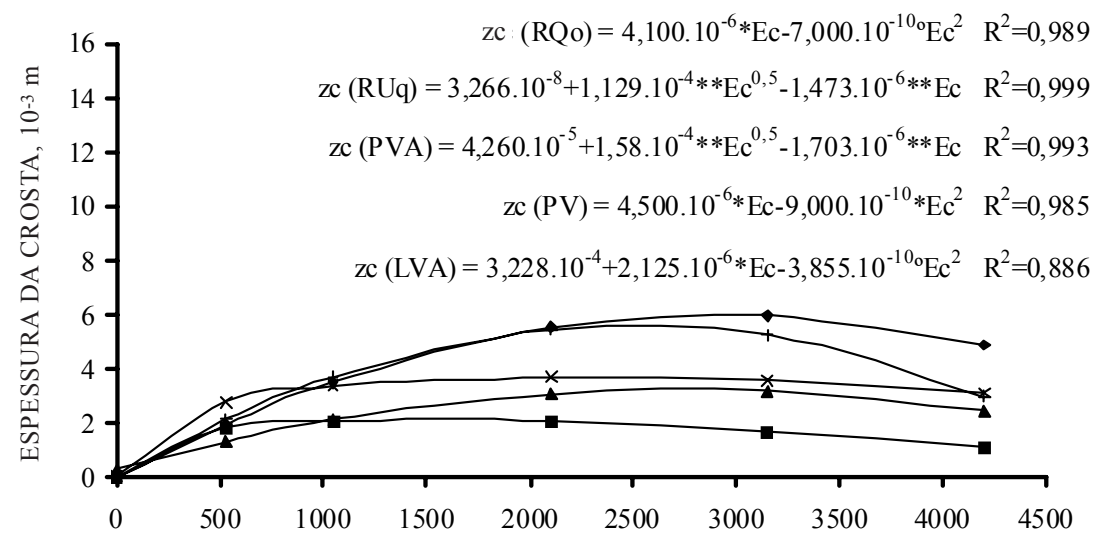

ENERGIA CINÉTICA, $\mathrm{J} \mathrm{m}^{-2}$

$-\mathrm{RQo} \rightarrow-\mathrm{RUq} \leftarrow \mathrm{PVA} \multimap \mathrm{PV} \leftarrow$ LVA

Figura 3. Espessura da crosta (zc), considerando a energia cinética aplicada (Ec) e a classe de solo (**, * $\mathrm{e}^{\circ}$ significativos a 1, 5 e $10 \%$, respectivamente, pelo teste $\left.\mathrm{t}\right)$. Sendo: $\mathrm{PV}=$ Argissolo Vermelho; $\mathrm{PVA}=$ Argissolo Vermelho-Amarelo; LVA = Latossolo Vermelho-Amarelo; $R U q=$ Neossolo Flúvico; $\mathrm{e}$ RQo = Neossolo Quartzarênico. 
O aumento da energia cinética levou à formação e ao aumento da espessura da crosta, que, após atingir um valor máximo, decresceu, mesmo com o aumento da energia cinética, em decorrência do desgaste da crosta provocado pelo aumento da tensão cisalhante do escoamento superficial associada aos maiores valores de energia cinética.

$\mathrm{Na}$ figura 4, são apresentados os gráficos e as equações ajustadas que relacionam a condutividade hidráulica da crosta e a energia cinética aplicada. Observa-se que, para o Neossolo Quartzarênico e o Argissolo Vermelho, houve um aumento da condutividade hidráulica da crosta à medida que a energia cinética aplicada aumentava. Como a crosta é composta por duas camadas distintas, a região de encrostamento externo ("skin seal") e a do encrostamento interno ("washed-in"), à medida que ocorreu o desgaste da crosta externa, que é mais compacta, a condutividade hidráulica da crosta aumentou. Embora o desgaste da crosta tenha sido um evento comum a todos os solos, este nem sempre promoveu aumento da condutividade hidráulica da crosta, o que pode ser atribuído à constante formação do encrostamento externo ou a valores muito baixos da condutividade hidráulica do encrostamento interno.

A forte compactação provocada pelo impacto direto das gotas de chuva levou ao decréscimo de condutividade hidráulica no Argissolo VermelhoAmarelo e no Neossolo Flúvico, corroborando para explicar o decréscimo da Tie observada nestes solos. Já o Latossolo Vermelho-Amarelo não apresentou variação da condutividade hidráulica da crosta na faixa de energia cinética aplicada. Neste caso, o decréscimo da taxa de infiltração pode ser atribuído somente ao aumento da espessura da crosta, conforme observado na figura 3 . O mesmo pode ser dito com relação ao Argissolo Vermelho e ao Neossolo Quartzarênico, uma vez que estes solos apresentaram aumento da condutividade hidráulica para aplicação de valores crescentes de energia cinética.

$\mathrm{Na}$ figura 5, são apresentados os gráficos e as equações ajustadas de resistência hidráulica da crosta para cada energia cinética aplicada e classe de solo. Os maiores valores de resistência hidráulica foram obtidos para o Argissolo Vermelho-Amarelo e Argissolo Vermelho. No entanto, todos os solos apresentaram um pico de resistência hidráulica, sendo seguido de um decréscimo decorrente do desgaste da crosta provocado pelo aumento da tensão cisalhante do escoamento superficial.

Utilizando regressão múltipla, ajustou-se a equação apresentada a seguir tendo como variável dependente a resistência hidráulica e independentes algumas características físicas e químicas do solo e a energia cinética da chuva. Desta forma, a partir desta Equação e do conhecimento de algumas características do solo e da chuva, é possível estimar a resistência hidráulica da crosta originada pelo impacto direto da gota e, a partir desta, estimar a taxa de infiltração em solos sujeitos ao desenvolvimento de encrostamento.

$$
\begin{aligned}
& \mathrm{Rc}=89599,32-665,65 * * \mathrm{AT}+635,40 * * \mathrm{St}+ \\
& 63378,00 * * * \mathrm{ADA} / \mathrm{Arg}-3833640,00^{* *} \mathrm{CO}- \\
& 175444,56^{* *} \phi_{\text {macro }}+0,72^{\circ} \mathrm{Ec} \quad \mathrm{R}^{2}=0,851
\end{aligned}
$$

em que $\mathrm{Rc}=$ resistência hidráulica da crosta, $\mathrm{s} ; \mathrm{AT}=$ teor de areia total, $\mathrm{kg} \mathrm{kg}^{-1}$; $\mathrm{St}=$ teor de silte, $\mathrm{kg} \mathrm{kg}^{-1}$; $\mathrm{ADA}=$ teor de argila dispersa em água, $\mathrm{kg} \mathrm{kg}^{-1}$;

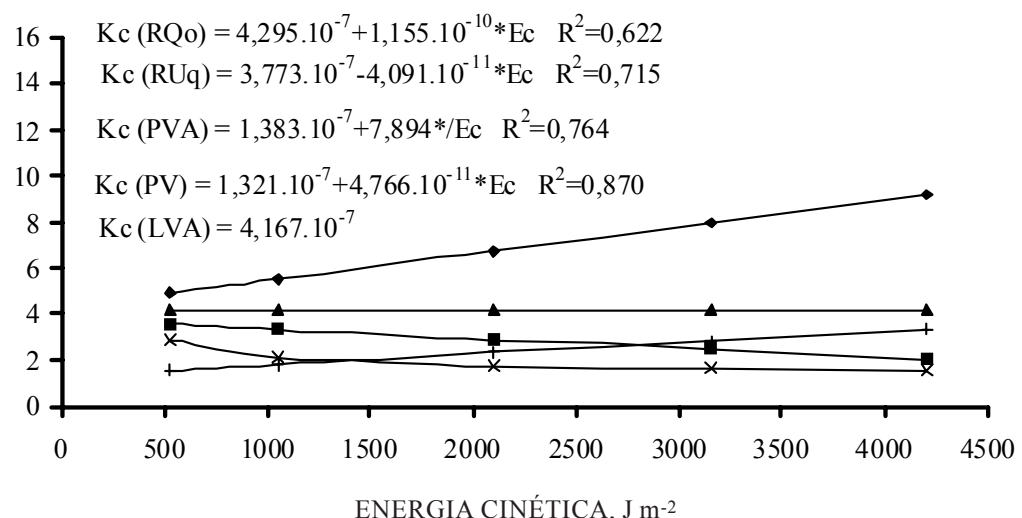

ENERGIA CINÉTICA, J m-2

$\leftrightarrow \mathrm{RQo} \rightarrow-\mathrm{RUq} \rightarrow \mathrm{PVA} \multimap \mathrm{PV} \rightarrow \mathrm{LVA}$

Figura 4. Condutividade hidráulica da crosta (Kc), considerando a energia cinética aplicada (Ec) e a classe de solo (* significativo a $5 \%$ pelo teste $\mathrm{t}$ ). Sendo: PV = Argissolo Vermelho; PVA = Argissolo Vermelho-Amarelo; LVA = Latossolo Vermelho-Amarelo; RUq = Neossolo Flúvico; e RQo = Neossolo Quartzarênico. 


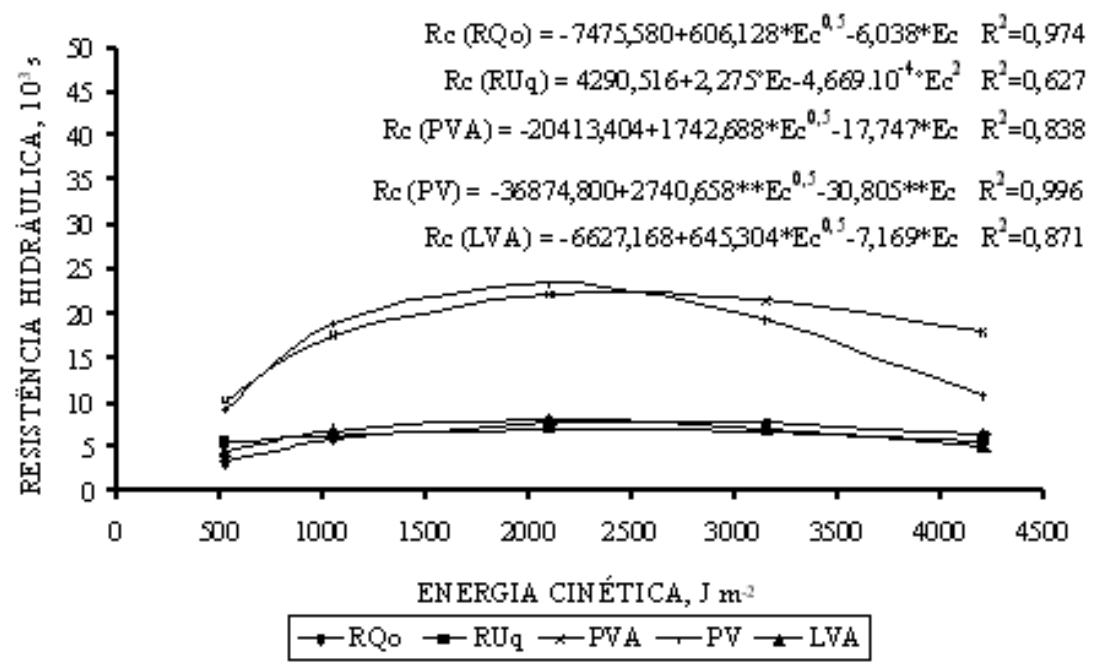

Figura 5. Resistência hidráulica da crosta (Rc), considerando a energia cinética aplicada (Ec) e a classe de solo (**, * e ${ }^{\circ}$ significativos a 1,5 e $10 \%$, respectivamente, pelo teste $\mathrm{t}$ ). Sendo: $\mathrm{PV}=$ Argissolo Vermelho; PVA = Argissolo Vermelho-Amarelo; LVA = Latossolo Vermelho-Amarelo; RUq = Neossolo Flúvico; e RQo = Neossolo Quartzarênico.

Arg $=$ teor de argila total, $\mathrm{kg} \mathrm{kg}^{-1} ;$ C.O. = teor de carbono orgânico, $\mathrm{kg} \mathrm{kg}^{-1} ; \phi_{\text {macro }}=$ macroporosidade da camada de $0-5 \mathrm{~cm}$ (anel volumétrico), $\mathrm{m}^{3} \mathrm{~m}^{-3}$; Ec $=$ energia cinética acumulada, $\mathrm{J} \mathrm{m}^{-2}, \mathrm{e}^{\circ}, * * * \mathrm{e} * * *$ significativos a $10,5,1$ e $0,1 \%$, respectivamente, pelo teste $t$.

Na citada equação, o sinal positivo da constante que multiplica a energia cinética indica que, à medida que esta aumenta, a resistência hidráulica da crosta também aumenta em decorrência do aumento da espessura e, ou, da redução da sua condutividade hidráulica. O sinal negativo da constante que multiplica a macroporosidade indica que o solo com maior valor desta variável (RQo) foi aquele que apresentou a maior taxa de infiltração.

A influência do teor de areia total no comportamento da resistência hidráulica da crosta está associada ao aumento da macroporosidade do solo. Desta forma, quanto maior a presença de areia, tanto menor a resistência hidráulica da crosta, o que explica o valor negativo da constante que multiplica o teor de areia. $\mathrm{O}$ oposto pode ser verificado para o teor de silte, uma vez que estas partículas preenchem os vazios do solo, dificultando a passagem de água para dentro do perfil do solo.

Os efeitos do teor de carbono orgânico do solo e da relação entre os teores de argila dispersa em água e argila devem estar associados, uma vez que a matéria orgânica é um dos fatores determinantes da agregação das partículas do solo. Sendo assim, quanto maior o teor de matéria orgânica do solo, maior será a sua estruturação, o que propicia uma menor resistência hidráulica da crosta, daí os valores das constantes dessas variáreis serem positivo e negativo, respectivamente.

\section{CONCLUSÕES}

1. Em todas as classes de solo avaliadas, evidenciou-se o desenvolvimento de encrostamento, caracterizado pela redução da taxa de infiltração, quando foram aplicados valores crescentes de energia cinética da chuva.

2. A partir das características de textura e estrutura do solo, pôde-se explicar o comportamento da infiltração em solos sujeitos ao encrostamento. Solos de textura arenosa ou solo argiloso de estrutura microgranular mantiveram as maiores taxas de infiltração em condições de encrostamento.

3. A análise micromorfológica mostrou-se eficiente na determinação das características físicas e hídricas da crosta.

4. A resistência hidráulica da crosta mostrou-se variável adequada a ser utilizada nos modelos de infiltração da água no solo para descrever a influência do encrostamento neste processo, uma vez que associa as características de espessura e condutividade hidráulica da crosta.

5. As variáveis mais efetivas na descrição do comportamento da resistência hidráulica da crosta foram a energia cinética da chuva, a macroporosidade da camada superficial do solo, os teores de areia total e silte, a relação (argila dispersa em água/argila total), o carbono orgânico e o grau floculação do solo.

\section{LITERATURA CITADA}

BARBIERI, J. Desenvolvimento de um linígrafo de baixo custo. Cascavel, Universidade do Oeste do Paraná, 1993. 21p. Não publicado. 
BRAKENSIEK, D.L. \& RAWLS, W.J. Agricultural management effects on soil water processes Part II: Green and Ampt parameters for crusting soils. Trans. Amec. Soc. Agric. Eng., 26:1753-1757, 1983.

BRESSON, L.M. \& BOIFFIN, J. Morphological characterization of crust development stages on an experimental field. Geoderma, 47:301-325, 1990

CHEN, Y.; TARCHITZKY, J.; BROUWER, J.; MORIN, J. \& BANIN, A. Scanning electron observations on soil crusts and their formation. Soil Sci., 12:49-55, 1980.

DULEY, F.L. Surface factors affecting the rate of intake of water by soils. Soil Sci. Soc. Am. Proc., 4:60-64, 1939.

EDWARDS, W.M. \& LARSON, W.E. Infiltration of water into soils as influenced by surface seal development. Trans. Amec. Soc. Agric. Eng., 12:463-465,470, 1969.

EMPRESA BRASILEIRA DE PESQUISA AGROPECUÁRIA EMBRAPA. Centro Nacional de Pesquisa de Solos. Manual de métodos de análise de solo. 2.ed. Rio de Janeiro, 1997. 212p.

EVANS, D.D. \& BUOL, S.W. Micromorphological study of soil crusts. Soil Sci. Soc. Am. Proc., 32:19-22, 1968.

FARIA, J.C.; SCHAEFER, C.E.G.R.; RUIZ, H.A. \& COSTA, L.M. Effects of weed control on physical and micropedological properties of brazilian ultisol. R. Bras. Ci. Solo, 22:731-741, 1998.

FERNANDES FILHO, E.I. \& VIANA, J.H.M. QUANTIPORO: um novo programa para tratamento e quantificação de imagens digitais para aplicações em ciência do solo. In: CONGRESSO BRASILEIRO DE CIÊNCIA DO SOLO, 28. Londrina, 2001. Resumos. Londrina, Sociedade Brasileira de Ciência do Solo, 2001. p.224.

GOLABI, M.H.; RADCLIFFE, D.E.; HARGROVE, W.L. \& TOLLNER, W. Macropore effects in conventional tillage and no-tillage soils. J. Soil Water Cons., 50:205-210, 1995.
McINTYRE, D.S. Permeability measurements of soil crusts formed by raindrop impact. Soil Sci., 85:185-189, 1958a.

McINTYRE, D.S. Soil splash and the formation of surface crusts by raindrop impact. Soil Sci., 85:261-266, 1958b.

MEIN, R.G. \& LARSON, C.L. Modeling infiltration during a steady rain. Water Res. Res., 9:384-394, 1973.

MURPHY, C.P. Thin section preparation of soil and sediments. Berkamsted, Academic Publisher, 1986. 149p.

NORTON, L.D. Micromorphological study of surface seals developed under simulated rainfall. Geoderma, 40:127-140, 1987.

OLIVEIRA, J.B.; JACOMINE, P.K.T. \& CAMARGO, M.N Classes gerais de solos do Brasil. Jaboticabal, FUNEP/ FCAV, 1992. 201p.

SANTOS, C.S.V. Formação de camadas superficiais adensadas em solo argiloso em resposta a flutuações de umidade do solo. Viçosa, Universidade Federal de Viçosa, 2000. 71p. (Tese de Doutorado)

SCHAEFER, C.E.G.R. Soils and paleosols from northeastern Roraima, north Amazonia: geomorphology, genesis and landscape evolution. Reading, University of Reading, 1994. 353p. (Tese de Doutorado)

SILVA, C.L. \& KATO, E. Avaliação de modelos para previsão da infiltração de água em solos sob cerrado. Pesq. Agropec. Bras., 33:1149-1158, 1998.

SLATTERY, M.C. \& BRYAN, R.B. Laboratory experiments on surface seal development and its effects on interrill erosion processes. J. Soil Sci., 43:517-529, 1992.

VALENTIN, C. \& BRESSON, L.M. Morphology, genesis and classification of surface crusts in loamy and sandy soils. Geoderma, 55:225-245, 1992. 